\title{
Correction to: Spatio-temporal variability of near-surface air temperature in the Dokriani glacier catchment (DGC), central Himalaya
}

\author{
Jairam Singh Yadav ${ }^{1,2} \cdot$ Bhanu Pratap $^{3} \cdot$ Anil K. Gupta $^{4,5}$ - D. P. Dobhal ${ }^{1} \cdot$ R. B. S. Yadav $^{2} \cdot$ Sameer K. Tiwari $^{1}$
}

Published online: 1 August 2018

(C) Springer-Verlag GmbH Austria, part of Springer Nature 2018

\section{Correction to: Theoretical and Applied Climatology https://doi.org/10.1007/s00704-018-2544-z}

The original version of this article unfortunately contained a mistake. Figures 4 and 5 captions were interchanged. The correct captions are given below.
Fig. 4 Annual cycle (i.e., mean monthly variation) of saturation vapor pressure lapse rate $(\mathrm{hPa} / \mathrm{km})$ in the Dokriani glacier catchment (DGC) during 2011-15
Fig. 5 Annual cycle of rainfall $(\mathrm{cm})$ and relative humidity $(\%)$ at Tela camp (TC), base camp (BC), and advance base camp $(\mathrm{ABC})$ in the Dokriani glacier catchment (DGC) during study period

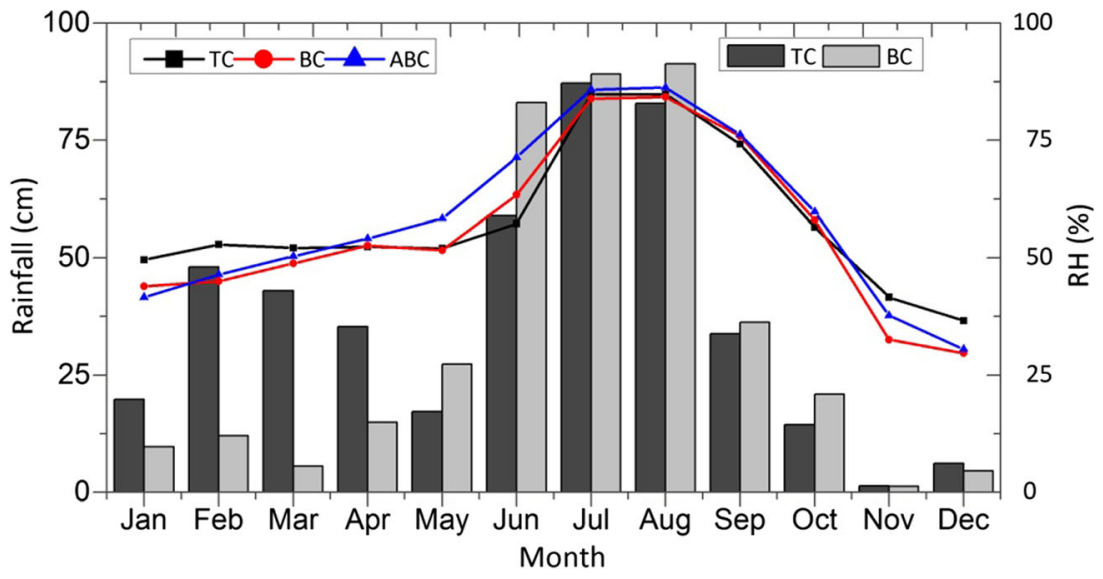

The online version of the original article can be found at https://doi.org/ 10.1007/s00704-018-2544-z

Jairam Singh Yadav

jai.au08@gmail.com; jai.geo08@gmail.com

1 Centre for Glaciology, Wadia Institute of Himalayan Geology, Dehradun 248001, India

2 Department of Geophysics, Kurukshetra University, Kurukshetra 136119, India

3 National Centre for Antarctic \& Ocean Research, Ministry of Earth Sciences, Headland Sada, Vasco da Gama, Goa 403804, India

4 Wadia Institute of Himalayan Geology, Dehradun 248001, India

5 Department of Geology and Geophysics, Indian Institute of Technology, Kharagpur 721302, India 